\title{
O processo de reformulação curricular de duas faculdades de Medicina no Brasil e na Argentina: uma abordagem comparativa*
}

Lilian Koifman

KOIFMAN, L. The process of curricular reform of two medical schools in Brazil and Argentina: a comparative approach, Interface - Comunic., Saúde, Educ., v.8, n.14, p.113-33, set.2003-fev.2004.

This work investigates, through a comparative approach, the process of curricular reform of the courses offered by two medical schools in Brazil and Argentina, namely, the Federal Fluminense University (UFF) and the University of Buenos Aires (UBA). We avail ourselves, as our starting point, of the Latin American higher education reforms and their discussions in the educational area. Our objective is to identify a set of tensions that manifests itself between the particular cultures of university organization, the desire for the uniformity of globalization and the quest for bureaucratic control derived from the regionalization of the Mercosur. Both countries are undergoing deep reform of their educational systems, articulated with the neoliberal policies of economic reform and the reduction of the role of the State in their respective societies. However, although there are formal similarities in several respects, the results of the analysis of the Brazilian and Argentinean realities reveal differences that should not be neglected.

KEY-WORDS: Medical education; higher education; curriculum; medical schools.

Investigamos, em uma perspectiva comparativa, o processo de reformulação curricular de dois cursos de medicina no Brasil e na Argentina: o da Universidade Federal Fluminense (UFF) e o da Universidade de Buenos Aires (UBA). Trabalhando com a metodologia do estudo de caso, utilizando a entrevista e a observação participantes como instrumentos, partimos do marco das reformas do ensino superior na América Latina e suas discussões na área de educação. Buscamos revelar um conjunto de tensões que se produzem entre as particulares culturas de organização universitária, as demandas pela uniformidade da mundialização e a busca do controle burocrático derivado da regionalização do Mercosul. Ambos os países estão passando por processos de profunda reformulação de seus sistemas educacionais, articulados com as políticas neoliberais de reforma econômica e de diminuição do papel do Estado nas respectivas sociedades. Resultados indicam que, mesmo existindo semelhanças formais em diversos aspectos, o exame das realidades brasileira e argentina revela diferenças que não devem ser negligenciadas.

PALAVRAS-CHAVE: Educação médica; educação superior; currículo; escolas médicas.

\footnotetext{
* Artigo elaborado a partir de Tese de Doutorado (Koifman, 2002), pesquisa realizada com recursos do CNPq e CAPES.

${ }^{1}$ Professora do Departamento de Planejamento em Saúde do Instituto de Saúde da Comunidade da Universidade Federal Fluminense ISC/UFF). <liliankoifman@hotmail.com>
} 
KOIFMAN, L.

\section{Apresentação}

Neste trabalho propusemos investigar o processo de reformulação curricular de cursos de Medicina no Brasil e na Argentina, estudando os casos da Universidade Federal Fluminense (UFF) e da Universidade de Buenos Aires (UBA).

Partimos do marco das reformas do ensino superior na América Latina e suas discussões na área de educação. Buscamos revelar um conjunto de tensões que se produzem entre as particulares culturas de organização universitária, as demandas pela uniformidade da mundialização e a busca do controle burocrático derivado da regionalização do Mercosul (a necessidade de equivalências de programas e títulos, uniformidade de condições de acesso etc).

Brasil e Argentina estão passando por processos de profunda reformulação de seus sistemas educacionais, articulados com as políticas neoliberais de reforma econômica e de diminuição do papel do Estado nas respectivas sociedades. Entretanto, mesmo existindo semelhanças formais em diversos aspectos, o exame das realidades brasileira e argentina revela diferenças que não devem ser negligenciadas.

A partir da comparação entre os processos de reformulação curricular das faculdades de Medicina da Universidade Federal Fluminense (UFF) e da Universidade de Buenos Aires (UBA), perguntamos: quais as aproximações $e$ divergências levando em conta cada contexto local e o contexto regional? Considerando que há um processo de integração curricular no Mercosul sendo desenvolvido, até que ponto tal processo está presente e influi nas discussões de reformulação curricular na UFF e na UBA? Quais são as motivações que, no contexto de crise dos sistemas públicos de educação e de saúde brasileiros $e$ argentinos e suas respectivas reformulações, orientam as reformas curriculares?

Essas questões foram investigadas a partir da comparação dos dois processos de reformulação curricular tomados como estudo de caso. Na comparação pudemos ver questões que se destacaram no caso brasileiro bem como no caso argentino, que apenas puderam ser devidamente dimensionadas quando contrapostas. As particularidades de cada caso passaram a receber a devida atenção e destaque a partir da abordagem comparativa.

Para Marginson \& Mollis (2002, p.584):

(...) realizar um trabalho de educação comparada sempre envolve tanto diferenças quanto semelhanças. Diferenças e semelhanças são oposições filosóficas, mas não são necessariamente antagônicas ou mutuamente exclusivas, nem na teoria nem na prática. Sistemas educacionais mostram diversidade em um aspecto e semelhanças em outro; a relação entre ambos pode ser mais complementar que antagônica.

A comparação toma maior relevo hoje justamente no modelo teórico da globalização ou mundialização, no qual os países periféricos são tratados de forma homogeneizada pelos órgãos de financiamento internacional, fazendo com que pareçam todos semelhantes, mesmo que, na verdade, suas diferenças e especificidades sejam mantidas ${ }^{2}$. 
${ }^{2}$ As propostas de reforma

educacional, de acordo com Gentili (1998), têm sua regularidade, verificada pela expansão de um mesmo núcleo de diagnósticos, propostas e argumentos acerca da crise educacional $e$ suas supostas saídas, assim como na circulação e no impacto que os

documentos $e$ recomendações do Banco Mundial e do FMI têm na definição das políticas públicas destinadas a esse setor. Nestas propostas, são a avaliação das instituições educacionais e o estabelecimento de critérios de qualidade que permitem

dinamizar o sistema, mediante uma lógica de prêmios e castigos que estimulam a produtividade e a eficiência.
As pressões externas aos governos centrais orientaram-se por diversificação de fontes de financiamento (venda de serviços e cobrança de taxas escolares), reformas curriculares (encurtamento dos cursos de graduação, para se obter mais rápida inserção no mercado de trabalho), seletividade no acesso (exames tipo vestibular), promoção de novos cursos orientados para o mercado (Marketing, Finanças, Sistemas etc.), atualização docente e rápida expansão de universidades particulares. Estas tendências formam parte de uma "agenda internacional" que se aplica na América Latina (assim como nos países póssocialistas da Europa) e constituem o contexto internacional em que se inserem as reformas universitárias atuais no Brasil e na Argentina (Mollis, 1999).

A América Latina está na periferia da mundialização e, dentro da América Latina, Argentina e Brasil estão ocupando um lugar central na nova agenda modernizante. Uma das estratégias para a implementação da nova agenda é o Mercosul.

Um dos traços destacados da mundialização capitalista na última década tem sido o aparecimento e consolidação de blocos econômicos regionais destinados a aumentar os níveis de intercâmbio comercial e de integração econômica regional. Os casos da União Européia, o Acordo de Livre Comércio da América do Norte, o bloco que reúne os países do Sudeste Asiático e o Mercado Comum do Sul, constituem os exemplos mais visíveis - ainda que apresentem notórias diferenças em suas dinâmicas e níveis de integração - desta tendência.

A evolução desses processos - e a cabal compreensão de suas conseqüências sociais - não pode estar desligada da hegemonia política e econômica do neoliberalismo. Neste sentido cabe assinalar que a evolução recente dos processos de integração (alguns deles de longa data, como no caso da União Européia) tem estado ligada ao que genericamente podemos chamar de "ideologia de mercado" e que em muitos casos tais processos tem servido para veicular ou aprofundar, em espaços regionais mais amplos, os preceitos econômicos ligados à mercantilização dos bens públicos. No caso europeu, por exemplo, a disciplina fiscal exigida pelos acordos de Maastricht e de Amsterdã para a construção da moeda única (o euro) serviu de ferramenta para a aplicação de políticas orçamentárias ortodoxas em escala nacional que tiveram um considerável impacto na retração do gasto público e no debilitamento dos direitos sociais e trabalhistas conquistados pelos assalariados depois da Segunda Guerra Mundial.

A ênfase da comparação realizada está no olhar institucional, inserido nas políticas e na tomada de decisões em cada caso e nos dois de forma comparada. Para isso utilizamos os dados coletados e analisados durante a pesquisa, mediante a realização de entrevistas e observação participante em reuniões $e$ seminários.

Marginson E Mollis (2002, p.583) afirmam:

(...) algumas pesquisas assumem a separação entre educação, política e poder. Acreditamos que no coração da pesquisa internacional de educação comparada, educação se cruza com poder. (...) as demandas do poder moldam as práticas do conhecimento. 
Partimos do pressuposto de que a educação médica, e por conseguinte a universidade, tem o papel de formar médicos que atendam às necessidades de saúde da população. Essa formação deve incluir tanto a visão humanista, o compromisso social, quanto a habilidade técnica competente e atualizada. $\mathrm{Na}$ realidade observada, muitas vezes tais princípios foram deixados em segundo plano e foram priorizadas as disputas pelo poder.

Os dois casos da Medicina, tanto no Brasil quanto na Argentina, formam parte da agenda de modernização. Como essa agenda - passada pelo Mercosul e outras 'fórmulas' - afeta a formação do médico?

Para responder a essas e outras perguntas apoiar-nos-emos no referencial teórico e nas entrevistas realizadas com informantes-chave - em sua maioria personagens com poder de decisão política - das duas reformulações curriculares, realizadas no decorrer do desenvolvimento da pesquisa.

Os processos de reformulação curricular: os casos da Faculdade de Medicina da UFF e da Faculdade de Medicina da UBA Nos dois casos, foram analisados os currículos de formação médica no Brasil e na Argentina, mais especificamente o processo de reformulação do currículo médico em ambos os países, estudando os casos da UFF e da UBA.

O processo de reformulação do currículo da Medicina da UFF, iniciado em 1983, foi concluído em 1992 e sua implantação começou a ser feita a partir de 1994 (Koifman, 2001).

A Faculdade de Medicina da Universidade de Buenos Aires (UBA), desde 1983, passou por várias tentativas de reformulação curricular. O mais recente processo de reformulação curricular inclui dois momentos: o primeiro durante os anos de 1999 e 2000 e o segundo a partir de dezembro de 2000 até 2002 (Koifman, 2003).

A escolha da Faculdade de Medicina da UFF como o caso brasileiro a ser analisado deve-se ao fato de que sua proposta de reformulação curricular tem sido considerada referência para a área de educação médica em congressos nacionais e internacionais. E que, desde sua implementação, o chamado 'novo currículo' continua a sofrer uma série de mudanças e adaptações, o que reflete o caráter dinâmico tanto da proposta, quanto da Faculdade de Medicina da UFF. Salientamos, ainda, o fato de termos tido a oportunidade de acompanhar o processo de reformulação curricular com 'observação participante', desde 1991 até sua implantação, em 1994.

A escolha da Faculdade de Medicina da UBA como o caso argentino a ser analisado deu-se por ela ser considerada a principal faculdade de Medicina na Argentina e por seus processos influenciarem grande parte do debate sobre a orientação e o perfil profissional do médico naquele país. Outro ponto de relevância é que atualmente a Faculdade de Medicina está discutindo seu currículo e elaborando uma nova proposta - processo vivenciando por meio da 'observação participante'.

O caso da UFF

O processo de reformulação curricular da UFF iniciou-se no final da década de 1970, a partir do descontentamento de alunos e professores com o ensino e aprendizagem realizados até então na instituição e com a inadequação do 
${ }^{3}$ As ações de integração docente-assistencial, envolvendo a

Universidade Federal

Fluminense e a

Secretaria Municipal de

Saúde de Niterói,

iniciaram-se

marcadamente a partir

da década de 1970 e

foram organizadas

como estratégias para

viabilizarem as

mudanças dos modelos

assistenciais e de

ensino/aprendizagem.

No final da década de

70 organizou-se a

construção da rede

básica de Saúde na

cidade, buscando-se

uma lógica de atenção

que fosse além da

assistência curativa. Esse

enfoque incluiu a

participação de alunos

de graduação da UFF na

rede de serviçose

incentivou a relação da

equipe com as

associações de

moradores das áreas de

abrangência das

Unidades de Saúde. No

início dos anos 80

implementou-se a

administração colegiada

das ações do município

(Comissão Executiva

Local) envolvendo as

várias instituições, a

regionalização e

organização hierárquica

dos serviçose

privilegiou-se também

a educação continuada

dos profissionais

(ênfase na formação de

gerentes em saúde). No

final da década e início

dos anos 1990 buscou-

se a reestruturação da

SMS visando o processo

de municipalização dos

serviços e a organização

das ações através da

constituição de

distritos sanitários

docente-assistenciais. A

construção teórica do

currículo de medicina

da UFF buscou obedecer

os princípios dessa

lógica, estruturado em

quatro programas:

Prático-Conceitual,

Teórico-Demonstrativo

Iniciação Científica $e$

Internato (Marins, J. J.

N. et al, 1992). currículo em relação às necessidades do sistema de saúde e da população ${ }^{3}$. Foi criado, então, um grupo de trabalho que elaborou uma proposta preliminar para ser discutida; porém o processo só foi retomado em 1983 . O grupo de trabalho concluiu, entre outras coisas, que o sistema de saúde não atendia às necessidades básicas de assistência médica da população e que era dada pouca ênfase à formação de professores e aos métodos de ensinoaprendizagem. "O ensino era voltado para a doença, predominando aulas teóricas e demonstrativas, utilizando-se situações fictícias em detrimento de práticas reais" (Koifman, 2001, p.58).

A efetiva elaboração de uma proposta de reformulação curricular só se desenvolveu após modificações profundas no sistema de saúde que, passando pelas Ações Integradas de Saúde (AIS) - com o Projeto Niterói - e pelo Sistema Unificado Descentralizado de Saúde (SUDS), chegaram à implantação do Sistema único de Saúde (SUS). A reorganização do sistema de saúde facilitou a implementação da nova proposta $e$ a inserção do profissional que o novo currículo passaria a formar.

O processo de reformulação curricular começou em 1983, mas a elaboração final da proposta deu-se em 1992 e foi implantada em 1994. Mas o processo não ocorreu com unanimidade, pois não houve consenso de todos departamentos da faculdade de Medicina quando da implantação do mesmo. Avaliamos que parte da falta de consenso entre os departamentos deveu-se ao fato de que as áreas da Medicina, representadas em parte pelos departamentos, têm diferentes objetos de trabalho e objetivos na formação dos futuros médicos. Durante o processo de reformulação não foi possível criar um verdadeiro diálogo e debate interdisciplinar (Koifman, 2001).

No modelo curricular proposto, a parte prática aumenta (Programa Prático Conceitual) à medida que a parte fundamentalmente teórica diminui (Programa Teórico Demonstrativo). Na primeira parte associa-se o conteúdo teórico a uma demonstração prática executada pelos docentes $e$, na segunda, completa-se uma prática executada pelos alunos, sempre baseada em uma discussão conceitual das ações e de seu referencial teórico (UFF, 1992).

Sobre as principais características do novo currículo, a introdução do estudante nas aulas práticas desde os primeiros períodos é um dos pontos inovadores. Os alunos são divididos em pequenos grupos e acompanhados por um preceptor nas atividades práticas e na posterior análise dos problemas encontrados e na elaboração de respostas a esses problemas (trabalho de campo supervisionado). Além disso, a introdução de matérias da área de história da Medicina e outras vinculadas à área de ciências sociais, também contribui para uma formação diferenciada e que amplia a capacidade dos alunos de compreensão e inserção na realidade como profissionais.

Uma das idéias centrais do novo currículo, a partir de um contato precoce dos estudantes com a população mesmo antes de serem médicos, tem sido a da formação mais humanista do profissional médico e sensibilização do mesmo para os problemas sociais associados às questões de saúde.

Atualmente o currículo, que formou sua primeira turma em dezembro de 1999, está aos poucos conseguindo avançar no sentido da integração de 
departamentos. Isso vem ocorrendo, segundo depoimento de professor do Instituto de Saúde da Comunidade (ISC) (março de 2000), como reflexo da melhor estruturação das disciplinas e do melhor domínio, por parte dos professores, do que seja a proposta curricular e de suas etapas.

As dificuldades, desde a implantação do currículo, com a organização do trabalho de campo persistem. Durante o primeiro ano do curso ainda não é possível realizar, plenamente, as atividades de campo previstas. Na opinião dos professores entrevistados, o problema continua centrado no treinamento de professores e preceptores para compreenderem claramente a proposta $e$ tornarem-se capazes de trabalhar melhor em suas atividades.

Mas, mediante uma pesquisa de avaliação da proposta curricular, desenvolvida por uma equipe de professores do ISC (Oliveira, 2001), os 44 alunos formados na primeira turma, ao responderem a um questionário, manifestaram-se favoravelmente ao currículo. Apesar de muitas críticas aos primeiros semestres do curso, os alunos consideram que sua postura profissional e a compreensão da realidade social foram fortemente influenciadas por esse currículo.

\section{O caso da UBA}

Na Faculdade de Medicina da UBA, desde 1986, surgiram as primeiras discussões sobre a reforma curricular e foram implantadas novas "experiências curriculares". O mais recente processo de reformulação curricular tem dois momentos: o primeiro durante os anos de 1999 e 2000 e o segundo a partir de dezembro de 2000 até a presente data (nosso acompanhamento foi até 2002). A interrupção de um processo e começo de outro deu-se em conseqüência da mudança de direção da faculdade: cada momento corresponde a duas gestões de dois diferentes decanos.

Os processos de discussão na década de 1980 estiveram inseridos no contexto de redemocratização do país e, conseqüentemente, das universidades públicas. A experiência de mudança que teve maior impacto e que foi comentada nas entrevistas que realizamos foi a introdução dos Módulos de Atenção Primária (MAPs) no ciclo biomédico (a partir do $2^{\circ}$ ano do curso), com três módulos de 64 horas em cada semestre. Tais módulos incluíam uma atividade prática nos centros de saúde, que aos poucos foi sendo reduzida até a substituição, em 1996, pela disciplina Medicina Familiar, que se estende até o ciclo clínico do curso.

Em 1992 foi elaborada uma proposta de modificação do currículo que gerou impacto e muita discussão, pois teve como premissa a criação de um exame de ingresso. A idéia trazia poucas variações nas disciplinas e uma proposta metodológica baseada nas atividades práticas.

Mas, como o Conselho Superior aprovou a proposta (em vigor) e não aprovou a implementação de um exame de ingresso, foi aplicado (em 1993) um plano piloto, o Plan B (no caso, uma proposta curricular). A intenção era provar, com o plano piloto, que a reformulação curricular só poderia ter sucesso se fosse reduzido o número de alunos por ano.

Com uma maior carga horária, os alunos que participaram do "Plan" B tinham contato com pacientes em hospital desde o primeiro período de curso e o ensino era tutorial. Um dos objetivos era a integração do Ciclo Biomédico 
${ }^{4}$ As críticas à experiência estiveram inseridas em disputas políticas e ao fato do decano que impulsionou a

implantação do projeto ter, também, implementado uma experiência de modificação na forma de ingresso dos alunos de medicina diferente do resto da universidade de Buenos Aires.

Especificamente com relação ao plano piloto, entre as críticas recebidas pela comissão que avaliou a experiência (e professores e alunos entrevistados): foram selecionados os alunos com melhores médias e não ao azar; não houve um grupo controle da experiência, já que o número de alunos que continuou com o currículo "normal" era muito superior ao do Plan B (dificultando qualquer comparação) $e$ portanto, não se poderia considerar a experiência para aplicar ao grupo todo de alunos.

${ }^{5}$ Em 1995, durante a segunda gestão do decano Dr. Luis Ferreira criou-se o Ciclo Pré-Universitário de Ingresso (CPI) amparando-se na Lei de Educação Superior de 1995 ( $\left.N^{\circ} 24.521 / 1995\right)$, que, no seu artigo ${ }^{\circ} 50$ estabelece que "... nas universidades com mais de cinquenta mil (50.000) estudantes, o regime de admissão, permanência e promoção dos estudantes será definido ao nível de cada faculdade ou unidade acadêmica equivalente". Porém a Universidade de Buenos Aires, através de seu reitor, não tinha acatado a Lei e criou-se uma situação de conflito entre a faculdade de medicina e a reitoria. Muitos alunos foram prejudicados por vários anos pois a Reitoria não concordava em emitir os diplomas de medicina para alunos que tivessem cursado o CPI em vez do

CBC. Em 1998 foi derrogado o CPI" (Koifman, 2003, p.42). com o Clínico desde o começo do curso, demonstrando que a redução do número de alunos significaria uma melhora na qualidade do ensino. Mas o "Plan" B foi muito criticado e a experiência foi interrompida em 1998, tendo a última turma terminado o curso em 20014.

Depois da experiência do Plan $\mathrm{B}$ e do Ciclo Pré-Universitário de Ingresso (o CPI) para substituir o CBC (Ciclo Básico Comum), primeiro ano dos estudos universitários da UBA, que funciona como um curso introdutório, de nivelamento e seleção (Mignone, 1998), que não foi uma reformulação curricular apenas para o curso de Medicina mas para toda a faculdade de Medicina ${ }^{5}$, a seguinte reformulação curricular elaborada não foi implementada. Desenvolveu-se durante os anos de 1999 e 2000 - e teve como uma das características principais a implementação da metodologia do aprendizado baseado em problemas (PBL). Quando a proposta foi concluída (elaborada a partir de reuniões de uma comissão delegada pelo decano e de mais de um ano de discussões de comissões interdepartamentais), houve uma mudança na direção da faculdade de Medicina e o novo decano deu início a um novo processo de reformulação.

O novo processo deu-se entre os anos 2001 e 2002 com objetivo de impulsionar um processo democrático e com palestras e debates entre profissionais convidados e professores da faculdade com experiências isoladas de reformulação dentro dos departamentos (cátedras). Após um ano de reuniões quinzenais, a coordenação do processo - decanato, secretaria acadêmica e secretaria de planejamento educacional - decidiu estimular o desenvolvimento da reformulação a partir das diversas experiências, gerando "motores de mudança". Não se optou por uma reformulação total do currículo mas, em seu lugar, por estimular reformulações que já estejam em processo nas cátedras e ajudar a divulgação e possível ampliação das experiências de êxito.

Após a breve descrição dos dois casos de reformulação curricular, apresentamos um levantamento mais detalhado dos dados relevantes que demonstram semelhanças e diferenças entre os casos, por meio de análise comparativa.

\section{Metodologia}

No caso das duas reformulações curriculares analisadas, a comparação foi feita por meio da metodologia de descobrimento de variáveis por contexto.

Quando usamos técnicas qualitativas para examinar fenômenos extraídos de um contexto, quanto mais perto se observa mais complexo será o critério usado na observação, e mais semelhanças se transformarão em diferenças. Nos estudos qualitativos baseados no estudo de caso complexo, nos quais há sempre mais para pesquisar do que pode ser abarcado, há um viés de prima facie (a primeira vista), com respeito à criação, de diferença $e$ incomensurabilidade entre os casos, tendendo a eliminar a possibilidade de comparação. Mas a comparação também pode ser usada para transformar fenômenos diferentes em semelhantes (Marginson \& Mollis, 2002, p.585). 
Os pontos considerados relevantes quanto a sua influência em ambas as reformulações curriculares, utilizados para descrever as diferenças são: os contextos sóciopolíticos, autonomia universitária e avaliação institucional, forma de ingresso dos alunos, importância do acompanhamento pedagógico, objetivos da formação médica (papel social do médico).

\section{Resultados da análise comparativa \\ Contexto sóciopolítico}

Quanto às influências do contexto político regional do Mercosul, no caso da reformulação curricular da UFF, na época da reformulação, não houve influência que possa ser determinada. Nesse caso o contexto político de maior influência não foi o do Mercosul mas o da Reforma Sanitária Brasileira, portanto mais local.

O projeto da Reforma Sanitária, sustentado por uma produção teóricocrítica, foi formulado a partir do movimento pela democratização da saúde que tomou corpo no Brasil durante a segunda metade da década de setenta. Entre outros fatores, o movimento, segundo Paim (1997, p.11) "teve a importância de questionar a concepção de saúde restrita à dimensão biológica e individual, além de apontar diversas relações entre a organização dos serviços de saúde e a estrutura social’. Os departamentos de Medicina Preventiva e Social $e$ as escolas de saúde pública ou seus equivalentes foram o braço acadêmico do movimento reformista .

Para Silva Júnior (1998), foram percorridos três caminhos para tornar a Reforma Sanitária viável: o legislativo-parlamentar, possibilitando a elaboração da Lei Orgânica de Saúde (nº 8.080 de 1990) e de leis Estaduais e Municipais; o sóciopolítico, procurando envolver a sociedade civil e suas organizações; o institucional, implementando um novo sistema de saúde mais identificado com os ideais de universalidade, eqüidade, integralidade na atenção da saúde.

A Reforma Sanitária foi um processo que passou pelas Ações Integradas de Saúde (AIS) e Sistema Unificado Descentralizado de Saúde (SUDS) e que sofreu a implantação distorcida do Sistema único de Saúde (SUS) mas não se confunde com os mesmos (Arouca, 1988). "Os esforços para a unificação e descentralização, bem como as tentativas de mudança do modelo assistencial hegemônico nos últimos anos, inscrevem-se nesse resgate" (Paim, 1997, p.12).

A reformulação curricular da UFF teve influências do movimento sanitário tanto nas discussões prévias quanto na elaboração de sua estrutura curricular. A lógica da proposta de reformulação está intimamente ligada aos ideais da Reforma Sanitária e sua busca de construção de um profissional médico integrado ao sistema de saúde público (Saippa, 2001). Um dos reflexos dessa influência pode ser traduzido pelo fato de os alunos, desde o início do curso de Medicina, desenvolverem a prática nas unidades de saúde e não somente no hospital universitário. $E$, diferente de outros currículos de Medicina brasileiros que também passaram por reformulações recentemente, os estudantes inserem-se na realidade em suas horas práticas de aula.

No caso da prática realizada pelos alunos de Medicina da UBA, a prática é 
${ }^{6}$ Em dezembro de 2001 o Ministério de Saúde e - Ministério de Educação brasileiros lançaram um programa de incentivo às mudanças nos cursos de medicina - o PROMED. O programa oferece apoio técnico e financeiro para as escolas médicas que entraram em processos de mudança que levem a um trabalho articulado com os serviços de saúde, à adoção de metodologias ativas de ensino-aprendizagem e à formação geral, crítica $e$ humanista (Feuerwerker, 2002). Mesmo que um dos objetivos centrais do PROMED tenha sido a gradual adequação dos currículos das escolas médicas às novas Diretrizes Curriculares, no caso brasileiro não parece haver uma única vertente explicativa para o movimento de reorientação dos modelos de atenção. A influência do Sistem único de Saúde sobre os processos de formação profissional é vista, por muitos segmentos, como uma possibilidade de ampliar a relevância social da universidade $e$, fundamentalmente, formar profissionais com perfil mais adequado às necessidades de saúde da população. desenvolvida principalmente nos hospitais (universitário e não universitário) e a proposta de reformulação não prevê, até o momento, modificação nesse campo. Isso denota uma menor articulação do currículo com o sistema público de saúde e com a formação do médico que conhece a prática do sistema no qual deverá atuar.

Tal questão também foi percebida durante as reuniões de reformulação curricular (tanto do processo anterior de reformulação curricular da UBA quanto o iniciado no final do ano 2000). A necessidade de articulação da formação do médico com as unidades básicas de saúde foi um tema pouco debatido que apareceu em três das mais de trinta reuniões assistidas. A primeira, uma reunião geral, na qual apareceram vários temas, a segunda, sobre o internato rotatório, em que se relatava a implementação do novo internato rotatório e que havia sido feita uma seleção de hospitais e unidades de saúde para a realização das atividades dos internos (pela primeira vez se falou sobre a prática nas unidades de saúde). E a terceira reunião quando apareceu o assunto mais especifico e se debateu a necessidade da mudança do sistema de saúde para que houvesse uma real mudança no perfil do profissional médico. Nessa reunião também se descreveu a aplicação do Programa de Atenção Primária em Saúde (PROAPS) $e$ a participação da Faculdade de Medicina da UBA no mesmo, debatendo sobre a necessidade de a faculdade de Medicina garantir que sejam formados profissionais preparados para trabalhar com a Atenção Primária em Saúde.

Sobre o referido programa - segundo as informações levantadas nas entrevistas -, em ambos os países, no momento da pesquisa, seriam utilizados recursos do Banco Interamericano de Desenvolvimento (BID) para o PROAPS, um programa de hierarquização da atenção primária na saúde.

O Ministério da Saúde argentino (pela Subsecretaria de Atenção Primária com o BID), lançou o Programa (PROAPS) a ser desenvolvido em cinco anos, com o empréstimo de 120 milhões de pesos. Por esse programa planejava-se construir novos centros de saúde equipados e comprar equipamento dos consultórios dos médicos de "cabeceira". A idéia do Ministério de Saúde seria a de apoiar economicamente as faculdades de Medicina para ampliar $e$ melhorar os currículos e orientá-los para a formação de médicos de primeiro nível de atenção à saúde.

Esse é um exemplo que indica uma forma de articulação entre as mudanças curriculares estudadas e as políticas sanitárias promovidas pelos organismos de financiamento internacional ${ }^{6}$.

Podemos supor que as recomendações das agências internacionais de financiamento (Banco Mundial, BID, FMI etc.) vêm influenciando a construção das políticas educacionais do Mercosul assim como a agenda para as reformas no setor saúde.

Costa (1998) descreve que os estudos sobre políticas públicas convergem para a idéia que os governos nacionais estão cada vez mais afetados pelos procedimentos de políticas supranacionais. Um aspecto relevante deste consenso é a compreensão do papel das organizações internacionais e de sua influência na definição de agendas políticas nacionais, definindo os temas substantivos a serem apreciados e configurando as políticas de governo.

"As mudanças econômicas, ideológicas e políticas definidas pelos 
especialistas do Banco Mundial apelam para a diminuição do papel do Estado e para o fortalecimento do mercado para financiar e oferecer cuidado à saúde" (Costa, 1998, p.129).

Esse tema também vem sendo debatido na literatura contemporânea na área das reformas educacionais.

Para Leher (2001), a participação do Banco Mundial não se limita à mera assessoria técnica, como os empréstimos fazem supor, visto que esta instituição, assim como o FMI, atua por meio de condicionalidades.

A recusa de uma política por determinado país pode levar o banco a não lhe conceder o seu aval, deixando-o à margem do mercado internacional de capitais (...) o que faz os governos com legitimidade corroída acatarem o fundamental de suas condições. (Leher, 2001, p.185) 7

Ao centrarmos nossa atenção na influência do Mercosul nas reformulações, percebemos que o ponto mais forte de influência do Mercosul Educativo ${ }^{8}$, além de gerar maior interesse de ambos os países em conhecer a formação médica de seus 'vizinhos', foi a discussão e elaboração das diretrizes curriculares.

Apesar de os representantes brasileiros nos grupos de trabalho do Mercosul Educativo terem apresentado as diretrizes elaboradas para criar uma padronização dos cursos brasileiros em 1999, a criação das diretrizes comuns para o Mercosul foram apresentadas mais recentemente. O ponto importante a ser considerado é que, no Brasil, o Ministério de Educação e Cultura já controlava anteriormente a expedição dos diplomas e essa medida não gerou impacto no currículo da UFF. No Brasil, para que uma escola médica seja habilitada, o Conselho Nacional de Educação (CNE) deve autorizar, obedecendo a um currículo mínimo (agora substituído pelas diretrizes curriculares ${ }^{9}$ ).

Talvez a necessidade de haver sempre controle e centralização das autorizações esteja relacionada com o grande número de faculdades particulares no Brasil, expansão muito anterior à da Argentina. Porém, na Argentina, a expedição de diplomas é responsabilidade da universidade, autonomia conquistada na Reforma de 1918. Nesse caso, a imposição de diretrizes curriculares externas gera um impacto significativo.

Principalmente quando algo choca com a autonomia universitária.

\section{Autonomia universitária $e$ avaliação institucional}

Na Argentina, até a Lei de Educação Superior de 1995, não havia nenhum órgão controlador nem avaliador das universidades. Só a partir de então, com a criação da Comissão Nacional de Avaliação e Acreditação Universitária (CONEAU), em 1996, teve início um processo voltado para o estabelecimento de um sistema de avaliação e acreditação das universidades.
7 "O modus operandi do Estado brasileiro configura um determinado modelo de privatização, guardando forte similaridade com as políticas do Banco Mundial para a educação latinoamericanae, particularmente, para suas universidades. Em essência, o banco determina que o modelo europeu de universidade - estatal, autônoma, pública, gratuita e baseada no princípio de indissociabilidade entre ensino, pesquisa e extensão - não é compatível com a América Latina" (Leher, 2001, p.155)

\footnotetext{
${ }^{8}$ Apesar do seu caráter essencialmente comercial, o Mercosul conta com um setor educativo em

funcionamento. Um mês depois da assinatura do Tratado de Assunção, realizouse, em Buenos Aires um encontro de técnicos, responsáveis e Ministros de Educação do Cone Sul para discutir a conveniência de incorporar ao processo de integração econômica iniciado entre os quatro países, a dimensão educativa. A partir desse momento, realizaram-se várias reuniões e, em 13 de dezembro de 1991, os Ministros de Educação da Argentina, Brasil, Paraguai e Uruguai assinaram um

Protocolo de Intenções que incluiu as áreas de:

"formação da

consciência cidadã

favorável ao processo

de integração;

capacitação de recursos humanos para contribuir para o desenvolvimento; harmonização dos sistemas educativos" (Piñon, 1997, p.187).
} 
${ }^{9}$ No Brasil a construção das diretrizes curriculares na área de saúde se deu em um processo entre os anos de 1999 e 2001, envolvendo ampla mobilização das escolas e dos atores da saúde, que conseguiram encaminhar suas propostas contra uma primeira versão apresentada $e$ considerada conservadora por esses mesmos atores. $O$ resultado foi que as diretrizes apresentadas para os cursos de medicina refletem as propostas dos movimentos de mudança existentes na área (ABEM, CINAEM etc).

${ }^{10}$ Em 1998, a Associação de Faculdades de Ciências Médicas da República Argentina (AFACIMERA) editou o documento "Carreras de riesgo: el caso de la medicina. Metodología, procesos y productos la formulación de los patrones y estándares previstos por la ley de Educación Superior".

\begin{abstract}
A CONEAU tem mandato legal para realizar avaliações externas, acreditar cursos de graduação e pós-graduação, avaliar projetos institucionais para a criação de novas instituições universitárias nacionais ou provinciais, e avaliar o desenvolvimento dos projetos para o posterior reconhecimento de instituições universitárias particulares pelo Ministério de Cultura e Educação. (Mollis, 2001, p.23)
\end{abstract}

Da mesma forma não existia um currículo mínimo ou parâmetros curriculares a serem seguidos pelas novas escolas de Medicina. Em geral, seguiam o modelo da Universidade de Buenos Aires, mas com autonomia e liberdade para suas próprias adaptações ou inovações.

Na década de 1990, com a abertura dos cursos de Medicina nas faculdades particulares, passa a existir preocupação com algum nível de controle $e$ regulamentação. E, a partir desta época, começam a ser implementados os projetos para os programas de avaliação e, fundamentalmente, o trabalho da CONEAU.

As discussões do Mercosul Educativo impulsionaram a necessidade de se estabelecer as diretrizes curriculares e os standards para os cursos de Medicina. Como foi considerado um curso de risco, em 1998 foi o primeiro a ter standards estabelecidos para acreditação (as outras carreiras consideradas de risco foram engenharia e agronomia) ${ }^{10}$.

As faculdades de Medicina públicas e privadas, com exceção da UBA, reuniram-se (1999) e levaram o pedido à CONEAU de adaptação dos standards dos EUA às necessidades locais. A CONEAU adaptou-os e devolveu-os em forma de Guia de Auto-Avaliação dos cursos de Medicina. Estabeleceu-se uma convocatória obrigatória acatada pela totalidade das faculdades de Medicina argentinas, com exceção da UBA. Os 184 indicadores dos standards dos EUA transformaram-se em 126 argentinos ("Guía de Autoevaluación de Carreras de Medicina. Convocatoria Obligatoria. Año 2000-2001").

No Brasil, a universidade não tem autonomia para expedir diplomas. Ou melhor, expede o diploma mas a carteira profissional depende do MEC. Além deste, há corporações que legitimam e concedem permissão para exercer a Medicina: Conselhos Regionais de Medicina, Conselho Federal de Medicina.

A cultura avaliativa, de certa forma instalada previamente no Brasil, também facilitou a implementação do programa de avaliação do MEC.

Desde a década de 1960 discutia-se no país a avaliação institucional. Foi a partir da Reforma Universitária de 68, implantada durante a ditadura militar, que se constituiu o sistema departamental e o novo padrão de carreira universitária, pondo fim às cátedras. O sistema de pós-graduação expandiu-se $e$ outras mudanças foram trazidas pela implantação do modelo chamado "norte-americano" de universidade. Esse substituiu os modelos clássicos alemão e francês - que exerceram forte influência nas universidades brasileiras até a década de 1960 - dando lugar à busca da racionalização das universidades, sobretudo as públicas, reatualizadas com mais força nas décadas de 1980 e 1990 (Paula, 2001). A Reforma Universitária, no contexto dos acordos MEC/USAID, trouxe embutidas as idéias avaliadoras, abrindo caminho para um sistema universitário que incluía a avaliação e a acreditação 
como parte inerente 11

Foi a partir do relatório da Comissão Nacional para a Reformulação da Educação Superior, em 1985, que o trinômio autonomia-avaliaçãofinanciamento desponta nas novas políticas e propostas para a universidade brasileira. As propostas apresentadas no relatório reatualizam várias medidas contidas na legislação referente à Reforma de 68 .

$\mathrm{Na}$ atualidade, a defesa da autonomia universitária pelo governo brasileiro tem inspiração neoliberal. Segundo Leher (2001, p.154), "para introduzir sua política, de autonomia, o governo teve de operar uma contradição: negar a autonomia universitária constitucionalmente estabelecida (art.207) por meio de sua ressignificação: "autonomia diante do Estado para agir livremente no mercado". Para reforçar essa declaração, o autor cita o provão (Exame Nacional de Cursos) e as diretrizes curriculares, entre outros, como estratégias que limitam a competência da universidade para definir o conhecimento a ser transmitido, a forma de transmissão e os temas a serem pesquisados.

No caso das universidades argentinas, as discussões a respeito da avaliação institucional começaram a desenvolver-se, fundamentalmente, a partir da década de 90, com a promulgação da Lei de Educação Superior em 1995. A Lei e decretos de lei passaram a criar órgãos responsáveis pela avaliação e acreditação do ensino superior.

A Lei foi promulgada em meio a inúmeros debates e manifestações contrárias a ela. A autonomia é um princípio fundamental na comunidade acadêmica argentina, promulgada na Reforma Universitária de Córdoba de 1918. Para os defensores da autonomia universitária, a avaliação, como foi desenhada na nova Lei de 1995 - de forma autoritária - é vista como uma intromissão indevida do Estado. A montagem do sistema de avaliação comum às universidades públicas e privadas, e que estimula o estabelecimento de critérios de eficiência e competitividade, é rejeitado pela maioria das universidades nacionais ${ }^{12}$.

O Exame Nacional de Cursos, 'Provão', aplicado gradualmente a todos os cursos desde 1996, no Brasil, sofre boicotes por parte do movimento estudantil ${ }^{13} e$, segundo os entrevistados do nosso trabalho, terá impacto nos conteúdos curriculares na medida que, futuramente, pode-se prever uma necessidade de adaptação dos currículos de Medicina às necessidades da prova. Como aconteceu com o vestibular, quando o segundo grau (atualmente ensino médio) aos poucos foi se transformando em um nível preparatório, apenas voltado para a prova e não para os objetivos iniciais do segundo grau ${ }^{14}$.

O Ministério de Educação argentino ainda não implementou um exame equivalente, embora tenha sido iniciada sua discussão com a possibilidade de que seja implementado futuramente. Essa não será a primeira vez que os dois países se inspiram um no outro para implementar sistemas de avaliação. Um exemplo anteriormente citado é o das diretrizes curriculares.

Dentro de tantas variáveis descritas que vêm influenciando, de uma ou outra forma, as reformulações curriculares estudadas, cabe perguntar qual o lugar e a participação da questão pedagógica nas reformulações. Nos dois casos observaram-se especificidades descritas no próximo item.
${ }^{11}$ A primeira experiência se instaurou através da avaliação das pósgraduações, na qual a Coordenação de Aperfeiçoamento de Pessoal de Nível Superior (CAPES), teve papel

fundamental. Em 1979, a CAPES realizou sua primeira avaliação institucional "por pares". $\mathrm{Na}$ segunda metade da década de 80 e toda a década de 90, o

Ministério de Educação e Cultura (MEC), passou a criar departamentos e órgãos com funções de avaliação e controle do ensino superior. Como exemplo podemos citar os seguintes órgãos:

Comissão Nacional de Reformulação da

Educação Superior, em 1985, o Grupo Executivo de Reformulação da

Educação Superior (GERES), em 1986, a Comissão Nacional de Avaliação, o Programa de Avaliação das

Universidades Brasileiras (PAIUB), em 1992, e o Exame Nacional de

Cursos, em 1996 (Cunha 1998).

12 Os órgãos criados pelo Ministério de Educação a partir da Lei são os seguintes: Conselho Nacional de Educação Superior (CNES), em 1993; Secretaria de Políticas Universitárias (SPU), em 1993;

Comissão de Acreditação Universitária (CAP), em

1994; Comissão Nacional de Avaliação e

Acreditação Universitária (CONEAU), em 1996.

Cada comissão de avaliação externa deverá ser constituída por pares nomeados pela CONEAU ou por entidades que a substituam, como a das universidades privadas. $\mathrm{Na}$ área específica da medicina, ainda foi criado um órgão com funções de avaliação e acreditação específicos na área do ensino médico: Associação Argentina de Escolas de Ciências Médicas da República Argentina (AFACIMERA). 
${ }^{13}$ Antes disso, algumas entidades vinham discutindo a necessidade de avaliar a qualidade da formação oferecida pelos cursos universitários, de forma a contribuir para a melhoria do ensino superior, como o Programa de Avaliação Institucional da Universidade Brasileira (PAIUB) e a Comissão Interinstitucional Nacional de Avaliação do Ensino Médico (CINAEM), que foram completamente ignorados pelo MEC. Há uma página na Internet, criada pelo movimento estudantil, convocando a um plebiscito para avaliar o provão

(<www. plebiscitoprovao. hpg.ig.com.br> Acesso em 07 jan 2003)

${ }^{14} \mathrm{Em}$ um documento produzido pela DENEM (Direção Executiva Nacional dos

Estudantes de

Medicina) em 27/02/

2002, o Exame Nacional

de Cursos (ENC -

Provão) é criticado: “... o tipo de avaliação proposto pelo MEC, o qual na verdade não consegue fazer um diagnóstico consistente da realidade das escolas e muito menos apontar caminhos de como as escolas devem melhorar. Ao contrário, o tipo de incentivo para melhoria que essas avaliações propiciam é o objetivo do corte de verbas para o conjunto geral de instituições de ensino e uma verdadeira

desqualificação do ensino, no momento em que as escolas se vêem tentadas a criar cursinhos pré-provão para melhorar seu desempenho.

\section{Acompanhamento pedagógico das reformulações}

Quanto às questões pedagógicas, no caso da reformulação curricular da UFF, não houve um acompanhamento pedagógico permanente. Apesar de realizada uma assessoria pedagógica, no final do processo, a mesma desenvolveu-se sem remuneração ou vínculo oficial com a universidade. Não foi instalada uma instância de avaliação pedagógica na implementação do currículo nem em sua continuidade, apesar de ter sido prevista a criação de uma equipe de avaliação pedagógica permanente do processo de implementação do currículo. Durante a primeira parte do processo também se contou com a assessoria de uma pedagoga de maneira extra oficial (não era um profissional contratado nem integrante do corpo docente da UFF na época).

Por outro lado, as sucessivas reformulações curriculares da UBA têm sido assessoradas e até coordenadas por equipes de pedagogas do quadro permanente de professores da Faculdade de Medicina da UBA. Sua função, na Secretaria de Educação Médica, é organizar e oferecer cursos de formação pedagógica para os professores da Faculdade de Medicina da UBA. Assim, nas reformulações curriculares, os processos têm sido acompanhados permanentemente por equipes pedagógicas. A pedagoga que coordena o processo de reformulação curricular de 2001/2002 é responsável, cnjuntamente com o secretário acadêmico da faculdade, pela recém-criada Secretaria de Planejamento Educativo.

O caso da reformulação curricular da Medicina da UBA tem esta característica particular. Apesar de contextualizado, o processo decisório político institucional inclui a perspectiva pedagógica e, em alguns momentos, até reforça o nexo da reformulação com os princípios da Lei de Educação Superior e preocupação em realizar a avaliação proposta pela CONEAU (em concordância com princípios da Associação de Faculdades de Ciências Médicas da República Argentina - A.FA.CI.ME.R.A). Nas entrevistas realizadas, pudemos concluir que o suporte pedagógico esteve também vinculado ao momento político e econômico, além dos aspectos técnicos pedagógicos.

Na literatura das reformas curriculares, em geral, são citados os aspectos pedagógicos técnicos e metodológicos como centrais para que efetivamente seja reformulado o currículo e modificado o ensino, além da reforma do conteúdo (a Faculdade de Medicina da universidade canadense de Mac Master, freqüentemente citada nos processos de reformulação da UBA, é um exemplo de reformulação com utilização da metodologia de aprendizado baseado em problemas). Porém, como produto de nossa pesquisa, chegamos à conclusão que a motivação política e econômica, no caso argentino, esteve muito presente, o que faz do mesmo um caso particularmente atrativo.

No que consiste a particularidade do caso argentino? Consiste em que, nos vários momentos de reformulação, desde a volta à democracia, é lançado mão de todo um aparato técnico pedagógico brutal mas, em última instância, com a mudança do decano (e mudança na linha política) muda tudo e o trabalho realizado até então volta à estaca zero. Ou seja, por mais que haja um aparato técnico pedagógico, a racionalidade é outra. E ela tem origens na história da Universidade de Buenos Aires e na faculdade de 
Medicina, ao mesmo tempo em que está fortemente afetada pelo movimento internacional de mundialização da economia.

Uma das discussões internas da universidade que afeta amplamente as reformulações curriculares é a do sistema de ingresso na universidade. $E$ como o tema gerou e gera discussões nas reformulações curriculares da Faculdade de Medicina da UBA, passaremos a detalhá-lo um pouco em seus reflexos nas duas faculdades em estudo.

\section{Sistema de ingresso universitário}

O sistema de ingresso nas universidades é um ponto com grandes diferenças entre as universidades públicas dos dois países e que influencia os processos de reformulação curricular. Na UFF os alunos são selecionados pelo exame vestibular, realizado pelos estudantes que terminam o ensino médio. Na UBA o ingresso dos alunos é irrestrito, ou seja, ao terminar o nível secundário de estudos os alunos automaticamente podem se inscrever para iniciar o CBC (Ciclo Básico Comum) ${ }^{15}$.

Em conseqüência do grande número de alunos que se inscrevem por ano para cursar o Ciclo Básico Comum na faculdade de Medicina (assim como em outras faculdades da UBA), o debate sobre as implicações da chamada "massificação"16 do ensino superior tem sido constante na faculdade e é um tema considerado central. Nota-se, neste sentido, a falta de discussão sobre a questão inserida no tema do financiamento universitário.

Ao afirmar a necessidade de se determinar um número de vagas por ano para a entrada de alunos na faculdade, o decano anterior (até 2000) ganhou impopularidade. Esse fato tem como raízes a própria cultura reformista (Reforma de Córdoba de 1918, na qual um dos princípios fundamentais foi a democratização do ensino universitário) e a posterior experiência da ditadura militar que estabeleceu o ingresso restrito de alunos por ano. Portanto, ainda que venha sendo debatida a idéia da dificuldade de organização do ensino para um número tão grande de alunos na faculdade de Medicina - principalmente no período de escassez de recursos determinado fundamentalmente pela política neoliberal em vigência ${ }^{17}$ defender ou atacar tal postura pode significar uma ruptura política importante.

No caso da mudança de decano da faculdade de Medicina, no final do ano 2000, parte do conflito gerado, que resultou em sua saída do cargo, foi visto pela maioria dos entrevistados como conseqüência do projeto de reformulação haver proposto a entrada de, no máximo, 1400 alunos para o segundo ano do curso de Medicina.

Os conflitos existentes na gestão que foi substituída foram decorrentes de fatores ligados à reformulação curricular, bem como a outros de origem na política universitária da faculdade de Medicina e sua inserção na UBA. Já a pressão de setores da faculdade discordantes da proposta do perfil de médico que seria formado e da metodologia de ensino proposta (ensino baseado em problemas) não foi tão forte. As especificidades da conexão entre o acadêmico e o político na faculdade de Medicina argentina chamaram-nos a atenção.

Na reformulação da UFF, por outro lado, grande parte das disputas entre
${ }^{15}$ No caso da

Universidade de Buenos

Aires, ainda que o

ingresso ao CBC seja

irrestrito e considerado

como primeiro ano de

estudos universitários,

o CBC funciona,

realmente, como um

curso introdutório e de seleção. Entre 1995 e

1997, por exemplo,

segundo informação da reitoria da UBA, uma média anual de 17.400 se perderam no caminho que vai do CBC até as faculdades (Mignone, 1998).

${ }^{16}$ A massificação do ensino superior se traduz no rápido crescimento da matrícula no ensino superior. Para mais detalhes ler Trindade, 2001.

${ }^{17} \mathrm{Na}$ América Latina, as políticas neoliberais implementadas a partir da década de oitenta seguindo os

lineamentos do

"Consenso de

Washington", foram os veículos da

"mercantilização" da esfera pública. Esse processo se deu tanto através da asfixia $e$ diminuição do orçamento

(conseqüência dos planos de ajuste promovidos pelos organismos de financiamento internacionais e implementados pelos governos da região) como da privatização de serviços públicos, cujo exemplo mais ilustrativo da década de noventa foi a

Argentina. Esta

transferência

progressiva de serviços públicos para a esfera privada, como a educação e a saúde, resultou em um crescimento do setor privado que, no caso da educação, tenta apropiar-se de maneira crescente da "rentabilidade educativa" tradicionalmente "retida" na esfera pública. 
os departamentos e sua discordância no processo de reformulação curricular - assim como um boicote na implementação do mesmo - esteve conectada com a discordância entre os departamentos nos objetivos da formação do médico estabelecidos no novo currículo. A formação de um médico mais inserido no meio social e preparado, também, para a solução dos problemas de saúde pública despertou questionamentos e debate na Faculdade de Medicina da UFF.

\section{Objetivos da formação médica/papel social do médico}

Ao que parece, a comparação entre os dois processos de reformulação curricular demonstra, no caso brasileiro, que o currículo foi reformulado baseado nas necessidades locais e com uma perspectiva de atender às demandas de saúde pública, integrado ao sistema público de saúde. No caso argentino, percebe-se uma tendência que responde a diferentes interesses, tanto a políticos internos da faculdade de Medicina, quanto às necessidades expressas pelos professores e seus departamentos, com objetivos de modernização da formação médica $e$ preocupação com a qualidade do profissional formado. Algumas falas de professores durante as reuniões de reformulação curricular da UBA ilustram nossa afirmação:

\footnotetext{
"Não vai haver mudança no currículo, até que a faculdade defina que médico deseja formar, que tipo de profissional quer". "A reformulação não deve ser mudar disciplinas mas mudar a mentalidade dos professores". "Esta faculdade tem uma história de que os alunos não se formam para atender às necessidades de saúde da população. E teriam que ser formados para o $1^{\circ}$ nível de resolução". "Somos profissionais mas somos cidadãos. Quando se melhorem as condições sociais se melhorará a saúde..".
}

(Entrevistas realizadas entre os anos de 2000 e 2001).

Não há dúvida de que a Saúde Pública está em crise na Argentina mas, apesar das declarações transcritas, durante as discussões nas reuniões de reformulação curricular não foi possível transformar a preocupação e vincular a formação médica com a resolução dos problemas de saúde pública do país. Sempre as discussões derivam na impossibilidade de resolução dos problemas já que são vistos como meramente financeiros.

Nos relatos durante as entrevistas apareceu diversas vezes que, nas várias tentativas de reformulação curricular da Medicina da UBA, não houve preocupação com as questões acadêmicas, mas, em seu lugar, com as de cunho político (política universitária que, por sua vez, está vinculada a disputas partidárias) e de orçamento.

Outro ponto interessante a ser observado é o fato de que, no caso da UFF, a reformulação curricular foi liderada pelo Departamento de Saúde da Comunidade (atual Instituto de Saúde da Comunidade), o que indica uma tendência clara de desenvolvimento da área de Saúde Pública e concentração de esforços para considerar uma área central no currículo.

Na reformulação da UBA, o departamento de Saúde Pública não tem tido nenhum papel central nem de destaque. O departamento de Pediatria, por 
outro lado, destaca-se mais quanto à representação nas reuniões de reformulação curricular e participação no processo.

\section{Discussão}

Reflexões que surgem da comparação

Algumas diferenças, nos dois casos investigados, devem ser levadas em conta em nossa discussão.

Para Almeida (1999), as mudanças curriculares no campo da educação médica podem ser classificadas, de acordo com seu plano de profundidade, em inovações, reformas ou transformações. Nos dois casos estudados poderse-ia descrever o caso da UFF como transformação enquanto o da UBA, em seus vários momentos, como inovação.

A reformulação curricular da UFF realmente constitui um processo longo, construído continuamente ao longo de um período, propiciando mudanças na organização e na lógica de todos os anos do curso, com ênfase principalmente na diversificação dos cenários de ensino-aprendizagem e na relação da teoria com a prática. Já as alterações descritas na UBA são pontuais, descontínuas, sem articulação clara entre os vários momentos, afetando um número limitado de disciplinas, algumas vezes nem ultrapassando o limite dos planos e intenções.

A escolha da Faculdade de Medicina da UFF como unidade de análise do caso brasileiro deu-se pelo fato de sua proposta de reformulação ter sido considerada referência para a área de educação médica em congressos nacionais e internacionais, tendo os professores envolvidos no processo sido convidados, inúmeras vezes, a relatar a experiência da UFF para as escolas de Medicina que começavam suas reformulações curriculares. $E$, ainda, por continuar a ser permantentemente revista, desde sua implementação, sofrendo uma série de mudanças e adaptações, o que reflete seu caráter dinâmico.

A Faculdade de Medicina da UBA foi escolhida como unidade de análise do caso argentino, por ser considerada a principal faculdade médica na Argentina, sendo boa parte do debate a respeito do perfil profissional do médico influenciado pelas reformulações ali desenvolvidas. A escolha deu-se, ainda, em função das recentes tentativas de mudanças curriculares realizadas na instituição e pelo interesse no fato de essa faculdade ter resistido a entrar no programa de avaliação do Ministério de Educação Argentino (Comissão Nacional de Avaliação e Acreditação Universitária).

A comparação entre as duas reformulações curriculares almejou enriquecer os resultados da pesquisa. Esse foi um dos principais motivos da opção pelo estudo comparado.

No contexto da mundialização e de tendência à homogeneização dos países, continua sendo necessária e útil a percepção das particularidades de cada país e compreensão da origem de suas diferenças e semelhanças.

Além da perspectiva de intercâmbio de profissionais médicos entres os dois países, pelos protocolos assinados no marco do Mercosul, foi necessário comparar para entender o impacto das agendas globais dos países centrais, impondo um modelo para os países periféricos. E quanto há de agenda internacional em ambas reformas, quanto de Mercosul e de particular $e$ 
${ }^{18}$ Sobre o significado $e$ a importância da implantação do Programa de Saúde da Família dentro do processo de construção do SUS ainda existe polêmica. As duas maiores "teses" partem de opiniões que consideram que o PSF é uma estratégia que tem o potencial de induzir a transformação do modelo de atenção ou que essa política é uma tradução das propostas de focalização e de "cestas básicas" para a população mais pobre.

19 "A Alma Ata teve importância fundamental na definição de uma proposta para organização mais democrática dos serviços de saúde: a atenção primária à saúde. Essa proposição influenciou profundamente 0 processo de formulação de políticas de saúde em toda a América Latina e no Brasil em particular". (Feuerwerker, 1998 p.136) específico na dinâmica da Argentina e do Brasil? Quanto há de cultura própria institucional? Quão eficientes foram os processos internos de reformulação?

Mesmo que a autonomia universitária, no caso argentino, seja historicamente consolidada, das duas reformulações curriculares analisadas o modelo argentino é o que se mostra mais dependente e influenciado pela macro economia.

Apesar da diferença constatada entre as duas reformulações curriculares, no ano de 2002 (finalização da pesquisa) ambos os países receberam recursos do BID para a implementação de programas ligados à Atenção Primária de Saúde. Tal fato reforça a idéia de que a percepção dos órgãos financiadores internacionais com relação aos dois países obedece à mesma lógica. A formação médica no Brasil e na Argentina, além de tendências concomitantes (Programa de Saúde da Família ${ }^{18}$, Médicos de Família), está valorizando os programas de Atenção Primária. O que significa isso? Por que países como Brasil e Argentina continuam tendo deficiência nessa área?

Por um lado, partindo da formação médica, a resposta nos remete à discussão do perfil do médico e da forma como vem se adaptando sob a influência das pressões de um mercado cada vez mais especializado e voltado para a Medicina privada com toda a tecnologia lucrativa que está em seu bojo (um aprofundamento da discussão do modelo biológico pode ser visto em Koifman, 2001).

Por outro, relacionamos os princípios do programa financiado pelo BID com as recomendações da Conferência de Alma-Ata $(1978)^{19}$, em relação à implantação de uma rede de atenção primária à saúde. Tal rede, além de democratizar os serviços de saúde, deveria baixar os custos da área de saúde nos países da América Latina.

Para Silva Júnior (1998), a Organização Mundial de Saúde passa a ser a maior difusora da filosofia de Atenção primária em Saúde e o Banco Mundial o principal financiador dessas políticas de saúde. Ao que parece, as recomendações que influenciaram as reformulações curriculares na década de 1980, incluindo os dois casos analisados, ainda estão em vigor. E a crítica que tem sido feita a esse tipo de política de saúde é a de que, embora os discursos oficiais falem de universalização do acesso, na prática é mantida a dualidade do sistema, oferecendo os cuidados primários para os segmentos menos favorecidos da população e a Medicina de ponta para os mais favorecidos.

Com a crise econômica mundial, aumentaram as críticas neoliberais às possibilidades de se manter as propostas universalizantes de prestação de serviços. Em seu lugar são lançadas propostas de modernização $e$ racionalização do papel do Estado. E, nesse contexto, várias propostas de atenção seletiva são formuladas e estimuladas pelos organismos financeiros internacionais como o BID e Banco Mundial.

Até que ponto tal discurso parece renovar-se permanentemente?

Durante a análise dos processos de reformulação curricular, por diversas vezes, questionamo-nos quanto aos objetivos de ambos os currículos e de suas lideranças. Parece-nos evidente que o financiamento de projetos $e$ linhas de pesquisa determina prioridades e objetivos. Na atual crise de 
financiamento público, influenciada pelas políticas de ajuste em ambos os países, é preciso se perguntar pelas conseqüências que acarretam as possibilidades de diversificação de fontes de financiamento que parecem condenar as universidades públicas a uma dependência crescente do financiamento internacional ou do setor privado (laboratórios etc.).

Qual o espaço para a reivindicação de recursos públicos para as universidades públicas? A Universidade de Buenos Aires, por exemplo, hoje tem em seu quadro docente cerca de $30 \%$ de professores ad honorem, ou seja, que trabalham sem receber salários. Esse será o ideal de financiamento, baseado em trabalho voluntário?

Dos resultados obtidos, ratificamos a luta em defesa da universidade pública e gratuita e a necessidade de aumento do investimento público para as universidades públicas. São vários os motivos e vários os casos de países em que as universidades públicas, passando a ser financiadas por grupos de empresários ou empresas privadas, mudaram seus objetivos acadêmicos "adaptando-se" às necessidades de tais financiadores.

\footnotetext{
A 'desinversão' universitária forma parte do mandato globalizador pelo qual se deixa a produção do conhecimento inovador nas mãos dos países altamente industrializados, ou seja, o desenvolvimento da pesquisa às universidades e empresas do norte. Na distribuição das funções mundiais do conhecimento, às nossas universidades corresponde o papel de treinadoras de recursos humanos desde que sejam "recursos" e não os currículos humanistas. (Mollis, 2001, p.18)
}

Nossa preocupação é com o compromisso da universidade pública em estar voltada para a necessidade de saúde da população, tanto na oferta de atenção primária (e portanto primeira) de saúde quanto ao acesso aos recursos tecnológicos mais modernos. Na área da formação médica, os profissionais devem ser formados para lidar com ambas as necessidades.

Outro elemento importante a ser considerado, embora não tenha sido objeto central do trabalho, é o perfil de cada uma das universidades e das escolas de Medicina em particular: ambas não têm o mesmo tipo de perfil de inserção no âmbito acadêmico e no âmbito dos serviços. Essas diferenças complementam a compreensão das características e das diferenças entre os dois processos.

Como descrevemos anteriormente, Niterói foi uma das cidades pioneiras na construção do SUS e o então chamado departamento de Saúde da Comunidade da faculdade de Medicina da UFF teve um papel fundamental durante esse processo de construção, com grande força política no contexto municipal. Não podemos deixar de relacionar boa parte da explicação das características da reformulação curricular da UFF com essa história.

No caso da UBA, a principal e mais tradicional universidade Argentina, o destaque principal dos currículos parece ter estado mais voltado para a produção científica em áreas básicas e tecnológicas, e menos voltado para a transformação do sistema público de saúde e seus problemas.

Essas diferenças aproximam-nos da compreensão das modificações realizadas nos dois casos estudados e geram indagações: 
${ }^{20}$ A partir do que foi relatado em duas das reuniões de

reformulação curricular e na Conferência de Educacão médica (2001), na Argentina será implementada uma reforma de saúde direcionada para a área de Atenção Primária em Saúde.
Como, no caso da Faculdade de Medicina da UBA, o projeto de reformulação curricular atual ainda está em desenvolvimento, cabe perguntar se esta implementação melhorará ou não a formação dos médicos. Se não for retomada a função social do médico, conectado com o sistema público de saúde, preparando os profissionais para trabalhar nesse sistema, o que acontecerá com a formação? Quais mudanças sofrerá o sistema público de saúde a partir do desenvolvimento de programas na área de atenção primária ${ }^{20}$ ? Considerando que a Faculdade de Medicina da UBA foi a única que resistiu por muito tempo a entrar no programa de avaliação do Ministério de Educação argentino (por intermédio da CONEAU), que implicações haverá na reformulação curricular quando o currículo for avaliado?

No caso brasileiro, do mesmo modo que existiu um movimento que influiu na elaboração das diretrizes curriculares para a área de saúde, existe um movimento para adequar o Provão e a avaliação do ensino das faculdades de Medicina ao perfil proposto pelos movimentos de mudança e pelas diretrizes curriculares. Isso pode significar que o Provão continue a existir, apesar de todos os protestos contra sua existência.

Neste caso, qual será o impacto do Provão no currículo da UFF? Haverá mudanças no currículo tendendo a uma adaptação aos requisitos do exame? Até que ponto a liderança do novo currículo continuará sendo do Instituto de Saúde da Comunidade ou envolverá outros departamentos? As mudanças nas lideranças da Faculdade de Medicina podem alterar o processo em curs $\phi$ ?

Estas perguntas poderão ser respondidas à luz da evolução dos currícul $\phi$ de Medicina das faculdades estudadas, nos próximos anos.

A resistência pela preservação de espaços democráticos conquistados passa a ser uma imposição da conjuntura para todos os que lutam pela Reforma Sanitária. Os obstáculos que se antepõem a esse projeto requerem, além de esforços pedagógicos e técnico-científicos, saídas substancialmente políticas.

(Paim, 2002, p.145)

\section{Referências}

ALMEIDA, M. J. Educação médica e saúde: possibilidades de mudança. Londrina: Ed. UEL; Rio de Janeiro: ABEM, 1999.

AROUCA, A. S. Reforma sanitária brasileira. Tema/Radis, n.11, p.2-4, 1988.

BRASIL. Constituição. Constituição da República Federativa do Brasil, de 5 de outubro de 1988. Brasília, 1989, artigo 198.

CONEAU. Guía de Autoevaluación de carreras de Medicina. Convocatoria Obligatoria. Año 20002001. Mimeografado.

CORDEIRO, H. Sistema Único de Saúde. Rio de Janeiro: Ayuri/ABRASCO, 1991.

COSTA, N.R. Políticas públicas, justiça distributiva e inovação: saúde e saneamento na agenda nacional. São Paulo: Hucitec, 1998.

CUNHA, L. A. Critérios de avaliação e credenciamento do ensino superior: Brasil e Argentina. In: 
KOIFMAN, L.

VELLOSO, J. (Org.) O ensino superior e o Mercosul. Rio de Janeiro: Garamond, 1998. p.17-51.

DIREÇÃO EXECUTIVA NACIONAL DE ESTUDANTES DE MEDICINA. DENEM. Material de análise para as CLs sobre o que foi produzido após o COBREM em relação ao Movimento de Transformação das Escolas Médicas, 2002. Mimeografado.

FEUERWERKER, L.C.M. Mudanças na educação médica e residência médica no Brasil. São Paulo: Hucitec/Rede Unida, 1998.

FEUERWERKER, L.C.M. Além do discurso de mudança na educação médica: processos e resultados. São Paulo: Hucitec; Londrina: Rede Unida; Rio de Janeiro: Associação Brasileira de Educação Médica, 2002.

GENTILI, P. A falsificação do consenso: simulacro e imposição na reforma educacional do neoliberalismo. Petrópolis: Vozes, 1998.

GOMEZ, J.M. Globalização da política. Mitos, realidades e dilemas. Praia Vermelha. Estudos de Política e Teoria Social, n.1, p.5-25, 1997.

KOIFMAN, L. O modelo biomédico e a reformulação do currículo médico da Universidade Federal Fluminense. Hist., Ciênc., Saúde - Manguinhos, v. 8, n.1, p.48-70, 2001.

KOIFMAN, L. O ensino médico no Brasil e na Argentina: uma abordagem comparativa. 2002. Tese (Doutorado) - Escola Nacional de Saúde Pública, Fundação Oswaldo Cruz, Rio de Janeiro.

KOIFMAN, L. A Reformulação Curricular do Curso de Medicina da Universidade de Buenos Aires (1986-2002). Rev. Bras. Educ. Méd., v.27, n.1, p.36-49, 2003.

LEHER, R. Projetos e modelos de autonomia e privatização das universidades públicas. In: GENTILI, P. (Org.) Universidades na penumbra: neoliberalismo e reestruturação universitária. São Paulo: Cortez/Clacso, 2001. p.151-88.

MARINS, J. J. N.; OLIVEIRA, G. S.; PIRES, A. C. Evolução do Sistema de Saúde de Niterói. Niterói, 1992. Mimeografado.

MARGINSON, S.; MOLLIS, M. The door opens and the tiger leaps: theories and reflexivities of comparative education for a global millenium: Comparative Education Review, v.45, n.4, p.581-615, 2001.

MIGNONE, E. F. Politica y Universidad: el estado legislador. Buenos Aires: Lugar Editorial/IDEAS, 1998.

MOLLIS, M. Las políticas de reforma universitaria: la lógica global y la respuesta local: el caso de la Argentina. Interface - Comunic., Saúde, Educ., n.5, p.75-94, 1999.

MOLLIS, M. La Universidad Argentina en tránsito. Buenos Aires: Fondo de Cultura Económica, 2001.

PAIM, J. S. Bases conceituais da Reforma Sanitária Brasileira. In: FLEURY, S. (Org.) Saúde e democracia: a luta do CEBES. São Paulo: Lemos, 1997. p.11-24.

PAIM, J.S. Saúde, política e reforma sanitária. Salvador: ISC/BA, 2002.

PAULA, M.F.C. A inserção da universidade na lógica racionalizadora do capital: casos USP e UFRJ. In: SILVA, W. C. (Org.) Universidade e sociedade no Brasil: oposição propositiva ao neoliberalismo na educação superior. Niterói: Intertexto; Rio de Janeiro: Quartet, 2001. p.15-56.

PIÑON, F.J. Educación y procesos de integración: el caso del Mercosur. In: RECONDO, G. (Org.)

Mercosur: la dimensión cultural de la integración. Buenos Aires: Ciccus, 1997. p.181-90.

OLIVEIRA, G. S. Comunicação pessoal. Niterói: UFF, 2001. 
SGUISSARDI, V. Políticas de Estado e políticas de educação superior no Brasil: Alguns sinais marcantes de dependência. In: MORISINI, M. C. (Org.) Mercosul/Mercosur: políticas e ações universitárias. Campinas: Autores Associados; Porto Alegre: Editora da Universidade, 1998. p.205-33.

SILVA JÚNIOR, A.G. Modelos tecnoassistenciais em saúde: o debate no campo da Saúde Coletiva. São Paulo: Hucitec, 1998.

TRINDADE, H. As metáforas da crise: da "universidade em ruínas" às "universidades na penumbra" na América Latina. In: GENTILI, P. (Org.) Universidades na penumbra: neoliberalismo e reestruturação universitária. São Paulo: Cortez/Clacso, 2001. p.13-43.

UNIVERSIDADE FEDERAL FLUMINENSE. Proposta de Currículo Pleno. Niterói: Faculdade de Medicina/ Centro de Ciências da Saúde/UFF, 1992.

KOIFMAN, L. El proceso de reforma curricular de dos facultades de Medicina en Brasil y Argentina: un abordaje comparativo, Interface - Comunic., Saúde, Educ., v.8, n.14, p.113-33, set.2003-fev.2004.

En este trabajo nos proponemos discutir, en una perspectiva comparada, el proceso de reformulación de dos facultades de medicina en Brasil y en Argentina: el de la Universidad Federal Fluminense (UFF) y el de la Universidad de Buenos Aires (UBA). Partimos del marco de las reformas de la educación superior en América Latina y sus discusiones en el área de educación. Buscamos revelar un conjunto de tensiones que se producen entre las particulares culturas de organización universitaria, las demandas por la uniformidad de la mundialización y la búsqueda del control burocrático derivado de la regionalización del Mercosur. Los dos países atraviesan procesos de profunda reformulación de sus sistemas educativos, articulados con las políticas neoliberales de reforma económica y disminución del papel del Estado en las respectivas sociedades. No obstante, aunque existan semejanzas formales en muchos aspectos, el examen de las realidades brasileña y argentina revela diferencias que no pueden ser ignoradas.

PALABRAS CLAVE: Educación médica; educación superior; currículum; escuelas medicas. 


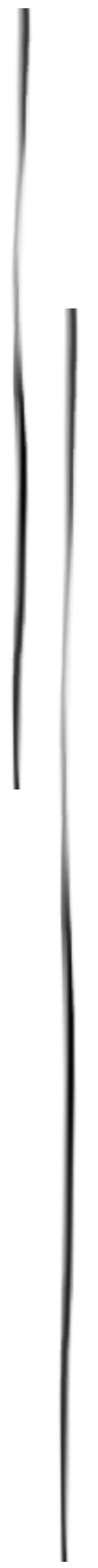

134 Interface - Comunic., Saúde, Educ., v.8, n.14, p.134, set.2003-fev.2004 